\title{
Pemberdayaan Wanita Kelompok Tani Hutan Melalui Diversifikasi Produk Hasil Hutan Bukan Kayu (HHBK)
}

\author{
Shintawati*, Zulfahmi, Ira Novita Sari, Livia Rhea Alvita \\ Jurusan Teknologi Pertanian \\ Politeknik Negeri Lampung \\ email:shintawati@polinela.ac.id
}

\begin{abstract}
KTH Agro Sumber Rejeki is one of the forest farmer groups located in the Register 40 production forest area in South Lampung Regency. This community service in the context of diversifying nontimber forest products (NTFPS), namely citronella oil. The purpose of this community service activity is to provide knowledge, technical production skills and quality requirements for citronella massage oil and telon oil, through empowering women from KTH Agro Sumber Rejeki. The method used in this PKM activity consisting of several stages, first technical guidance for making telon citronella oil and citronella sequence oil with 3 variants: natural, lemon and rose as well as counseling on herbal medicine quality requirements The effectiveness of PKM activities is evaluated by carrying out a pretest and postest. The average postest score was 83.53, an increase of 49.41 points from the pretest score with a total score of 100. The evaluation results showed that there was an increase in knowledge and technical skills in making telon citronella oil and citronella massage oil and also understanding the quality requirements of herbal medicines in women of KTH Agro Sumber Rejeki.
\end{abstract}

Keywords: Citronella, Massage Oil, Telon Oil

\begin{abstract}
Abstrak
KTH Agro Sumber Rejeki merupakan salah satu kelompok tani hutan yang berada di kawasan hutan produksi Register 40 Kabupaten Lampung Selatan. Kegiatan pengabdian masyarakat ini dalam rangka diversifikasi produk berbasis hasil hutan bukan kayu (HHBK) yaitu minyak sereh wangi. Tujuan dari kegiatan pengabdian masyarakat ini adalah untuk memberikan pengetahuan, keterampilan teknis produksi dan persyaratan mutu minyak urut dan minyak telon citronella melalui pemberdayaan kaum wanita KTH Agro Sumber Rejeki. Metode yang digunakan pada kegiatan PKM ini terdiri dari beberapa tahap yaitu penyuluhan persyaratan mutu obat herbal dan bimbingan teknis pembuatan minyak telon citronella dan minyak urut citronella dengan 3 jenis yaitu natural, lemon dan rose. Efektifitas kegiatan PKM dievaluasi dengan melaksanakan pretest dan postest. Rata-rata hasil nilai postest adalah 83,53, meningkat 49,41 poin dari nilai pretest dengan total nilai 100. Hasil evaluasi kegiatan tersebut menunjukkan adanya peningkatan pengetahuan dan keterampilan teknis pembuatan minyak telon citronella dan minyak urut citronella serta pemahaman syarat mutu obat herbal pada kaum wanita KTH Agro Sumber Rejeki.
\end{abstract}

Kata Kunci : Citronella, Minyak Urut, Telon

\section{PENDAHULUAN}

Kawasan hutan sudah cukup banyak dirambah oleh masyarakat. Salah satu upaya mempercepat proses rehabilitasi hutan dilakukan dengan melibatkan masyarakat dalam pengelolaan hutan. Pola yang diterapkan berupa agroforestri, yaitu menanam tanaman semusim disela tanaman hutan, atau yang dikenal dengan hasil hutan bukan kayu (HHBK). Melalui program hasil hutan bukan kayu (HHBK) selain hutan menjadi lestari juga dapat meningkatkan pendapatan petani hutan dari hasil tanaman non kayu (Indrasari D., et.al., 2017). Kelompok petani hutan (KTH) Agro Sumber Rejeki, merupakan salah satu kelompok binaan Kesatuan Pengelolaan Hutan (KPH) Gedong Wani yang berada di wilayah Register 40, Desa 
Sidoarjo Kabupaten Lampung Selatan. Luas Desa Sidoarjo $1.004 \mathrm{Ha}$ dengan rincian $12,5 \%$ dari luas wilayah tersebut adalah pemukiman dan $76,1 \%$ merupakan ladang atau tegalan. Sejak tahun 2016 KTH telah menanam sereh wangi sebagai tanaman sela. Tahun $2018 \mathrm{KTH}$ telah memproduksi minyak sereh wangi secara rutin 2,5 liter per hari. Kendala yang dihadapi saat ini adalah keterbatasan pasar. Jumlah pengumpul yang ada di Provinsi Lampung hanya satu perusahaan dan berada di luar Kabupaten Lampung Selatan. Hal ini mengakibatkan harga jual minyak sereh wangi dikendalikan oleh pasar dengan nilai yang jauh lebih rendah. Salah satu cara untuk mengatasi permasalahan KTH adalah hilirisasi produk minyak sereh wangi melalui diversifikasi produk berbahan dasar minyak sereh wangi. Diversifikasi hasil agroforestri akan meningkatkan macam produk yang dihasilkan sehingga dapat meningkatkan ekonomi masyarakat sekitar hutan (Indrasari D. et.al., 2017). Kendala lain yang dihadapi adalah keterbatasan pengetahuan masyarakat akan manfaat fitofarmaka yang terdapat dalam minyak sereh wangi, terbatasnya keterampilan masyarakat dalam mengolah minyak sereh wangi menjadi produk jadi serta rendahnya pemahaman masyarakat akan persyaratan obat herbal. Tujuan dari kegiatan pengabdian masyarakat ini adalah untuk memberikan pengetahuan, keterampilan teknis produksi produk berbasis minyak sereh wangi dan penyuluhan manfaat fitofarmaka serta persyaratan mutu sediaan herbal, melalui pemberdayaan kaum wanita KTH Agro Sumber Rejeki.

Minyak sereh wangi dengan nama dagang citronella merupakan minyak atsiri yang secara komersial diperoleh dari distilasi uap daun sereh wangi. Indonesia dan Cina merupakan negara pengekspor minyak sereh wangi terbesar di dunia (Nollet, L.M.L. et.al., 2017). Sejak zaman dahulu minyak sereh wangi telah digunakan sebagai antibakteri, antijamur, insektisida alami, pengusir nyamuk dan lalat. Pengobatan Cina menggunakan minyak sereh wangi sebagai minyak urut, pengobatan rematik, penghilang rasa sakit dan masyarakat Brazil menggunakan minyak sereh wangi sebagai analgesik. Zat aktif utama dalam minyak sereh wangi antara lain citronelal, citronelol dan geraniol. Kadar citronelal, citronelol dan geraniol dalam minyak sereh wangi Jawa masing-masing sebesar 21,59\%, 7,43\% dan 34,27\% (Eden W. T., et al., 2018). Citronelal atau rhodinol yang terkandung dalam minyak sereh wangi memberikan aroma lemon, geraniol dan citronelol menghasilkan aroma mawar. Pengembangan produk berbasis minyak sereh wangi telah banyak dilakukan, Setyaningsih D., et.al., 2010, mengaplikasikan minyak sereh wangi dalam pembuatan skin lotion. Muhtaridi, 2010 mengembangkan produk roll on melalui penambahan bahan kimia, produk sabun dan krim pijat. O. I. Adeniran et.al., 2012, mengembangkan formulasi cream anti nyamuk serta Nirwana, W.O.C. et.al., 2016, mengkaji produk lotion repelan nyamuk dari campuran minyak sereh wangi dan minyak nilam. Hongratanaworakit, T. et.al., 2018, mengembangkan minyak urut untuk menghilangkan nyeri otot menggunakan minyak kayu putih, minyak nilam, minyak lavender, minyak peppermin, minyak rosemary dengan zat pembawa berupa minyak jojoba, dengan hasil minyak urut yang dihasilkan stabil dan aman, tidak menimbulkan iritasi bagi konsumen. Penggunaan minyak atsiri yang mengandung zat aktif dengan masingmasing kemanfaatannya, telah dibuktikan mampu memperbaiki kualitas tidur (Chang, Y., et.al., 2017). Beberapa manfaat minyak atsiri bagi kesehatan menurut Ali, B., et al., 2015 seperti tertera dalam Tabel 1 berikut :

Tabel 1. Manfaat Beberapa Minyak Atsiri Nama Minyak Manfaat Atsiri 


\begin{tabular}{ll} 
Minyak Sereh & Meringankan \\
Wangi & kelelahan \\
Lemon & Obat Insomnia, \\
& meningkatkan sistem \\
& imun \\
Rose & Mengatasi kelelahan \\
& dan kehilangan \\
& memori \\
\hline
\end{tabular}

\section{METODE PENGABDIAN}

Pengabdian ini dilakukan dengan metode penyuluhan kandungan kimia fitofarmaka dan manfaat minyak citronella, sosialisasi persyaratan mutu obat tradisional serta pelatihan teknis pembuatan minyak telon dan minyak urut citronella. Kegiatan PKM ini melibatkan 17 orang wanita dari KTH Agro Sumber Rezeki. Evaluasi kegiatan secara kuantitatif dilaksanakan sebelum dan sesudah kegiatan berlangsung melalui pretest dan posttest secara tertulis. Evaluasi bertujuan untuk mengetahui tingkat keterserapan masyarakat akan materi yang disampaikan dan mengukur keterampilan peserta dalam membuat minyak telon dan minyak urut citronella. Peralatan yang digunakankan antara lain : kompor, panci, sendok pengaduk, gelas aluminium, gelas takar, botol, stiker dan lap. Bahan yang diperlukan antara lain : minyak kelapa, minyak citronella, vaselin, minyak kayu putih, minyak atsiri lemon dan minyak atsiri mawar (rose) dan minyak adas.

\section{HASIL DAN PEMBAHASAN}

Pengabdian ini dilakukan dengan metode penyuluhan, sosialisasi, diskusi serta pelatihan teknis.

a. Kegiatan penyuluhan kandungan kimia fitofarmaka dan manfaat minyak citronella serta bahan alam lainnya. Kegiatan ini bertujuan untuk memberikan pemahaman dan membuka wawasan masyarakat akan sifat fitofarmaka serta manfaat yang dimiliki oleh minyak citronela maupun bahan baku alam lainnya yang digunakan dalam membuat citronella massage oil.

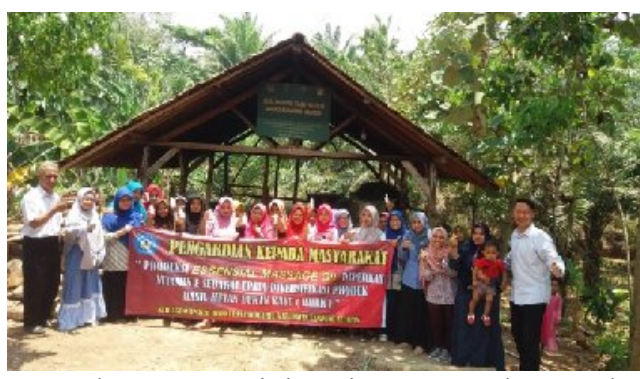

Gambar 1. Partisipasi Masyarakat pada

Penyuluhan Kandungan Kimia

Fitofarmaka Dan Manfaat Minyak Citronella

Partisipasi masyarakat pada kegiatan penyuluhan dan pelatihan teknis sangat baik, kaum wanita kelompok tani antusias mengikuti kegiatan sebagaimana Gambar 1.

b. Kegiatan bimbingan teknis pembuatan citronella massage oil, dengan 3 varian : original, lemon dan rose dan citronella massage oil for baby (minyak telon). Kegiatan bimbingan teknis ini bertujuan untuk melatih keterampilan teknis dan membuka wawasan anggota KTH cara membuat obat herbal yang tepat dengan memperhatikan sifat fisika dan kimia bahan-bahan yang digunakan. Kegiatan bimbingan teknis ini membuka wawasan peserta untuk mengolah dan membudidayakan HHBK lainnya yang digunakan dalam pembuatan citronella massage oil, seperti minyak atsiri lemon, minyak atsiri kayu putih, vaselin, minyak adas, minyak atsiri mawar dan kelapa. Gambar 2 memperlihatkan praktek pembuatan citronella massage oil oleh narasumber. 


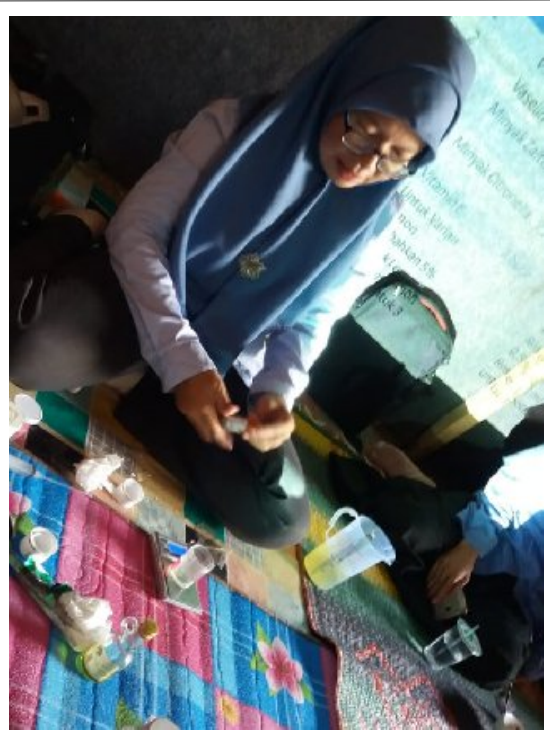

Gambar 2. Bimbingan teknis pembuatan citronella massage oil dan citronella massage oil for baby (minyak telon)

c. Kegiatan sosialisasi Peraturan Kepala Badan Pengawas Obat dan Makanan Republik Indonesia nomor 12 tahun 2014 tentang Persyaratan Mutu Obat Tradisional. Sosialisasi ini bertujuan untuk memberikan pemahaman berbagai jenis sediaan obat herbal serta persyaratan mutu yang perlu dipenuhi oleh obat herbal.

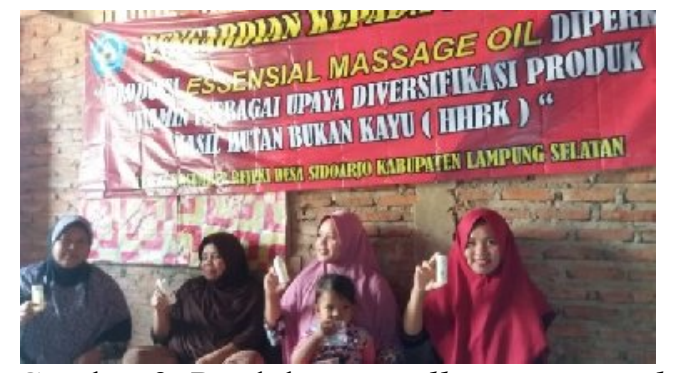

Gambar 3. Produk citronella massage oil dan citronella massage oil for baby (minyak telon)

Kegiatan PKM juga mencakup teknik pengemasan dan pelabelan yang baik. Gambar 3 memperlihatkan kaum wanita tani dan produk citronella massage oil dan citronella massage oil for baby (minyak telon) yang telah dikemas dan diberi label.

\section{Evaluasi Kegiatan PKM}

Evaluasi awal (pretest) dilaksanakan sebelum dimulainya penyuluhan dan bimbingan teknis. Evaluasi akhir (post test) dilaksanakan untuk mengevaluasi tingkat pemahaman dan keterampilan peserta setelah dilakukan penyuluhan dan bimbingan teknis. Materi evaluasi berupa pertanyaan-pertanyaan yang berkaitan dengan materi penyuluhan dan bimbingan teknis. Materi evaluasi dibuat sedemikian rupa sehingga dapat diketahui tingkat pemahaman peserta sebelum dan sesudah kegiatan. Hasil evaluasi kegiatan sebagaiman Tabel 1, sebagai berikut :

\begin{tabular}{cccc}
\multicolumn{4}{c}{ Tabel 1. Hasil Evaluasi } \\
\cline { 1 - 3 } $\begin{array}{c}\text { No. } \\
\text { Peserta }\end{array}$ & \multicolumn{2}{c}{ Hasil Evaluasi } & $\begin{array}{c}\text { Peningkatan } \\
\text { skor }\end{array}$ \\
\cline { 2 - 3 } & Awal & Akhir & \\
\hline 1 & 20 & 70 & 50 \\
2 & 30 & 70 & 40 \\
3 & 40 & 80 & 40 \\
4 & 20 & 90 & 70 \\
5 & 20 & 90 & 70 \\
6 & 40 & 80 & 40 \\
7 & 20 & 70 & 50 \\
8 & 50 & 90 & 40 \\
9 & 60 & 80 & 20 \\
10 & 20 & 80 & 60 \\
11 & 20 & 80 & 60 \\
12 & 50 & 80 & 30 \\
13 & 50 & 90 & 40 \\
14 & 40 & 90 & 50 \\
15 & 30 & 80 & 50 \\
16 & 40 & 100 & 60 \\
17 & 30 & 100 & 70 \\
\hline Rata- & & & \\
rata & 34,1 & 83,53 & 49,41 \\
\hline & & &
\end{tabular}

Tabel 1 menujukkan rata-rata nilai evaluasi awal adalah 34,1 dengan nilai tertinggi 60 yang diperoleh dari 1 orang peserta dan nilai terendah 20 diperoleh dari 6 orang peserta. Hal ini menunjukkan pengetahuan peserta sebelum dilakukan pelatihan sangat rendah. Setelah 
dilaksanakan penyuluhan dan bimbingan teknis, nilai evaluasi akhir menunjukkan peningkatan menjadi 83,53 atau meningkat $49,41 \%$ dari nilai evaluasi awal. Nilai terendah dari evaluasi akhir adalah 70 dan nilai tertinggi 100 , hal ini menunjukkan materi pelatihan mampu diserap oleh peserta dengan baik. Upaya promosi produk-produk berbasis minyak sereh wangi telah dilakukan oleh KTH dengan ikut serta pada kegiatan pameran pembangunan yang diselenggarakan oleh Pemerintah Provinsi Lampung dan mendapat apresiasi cukup baik dari masyarakat.

\section{SIMPULAN}

Pengabdian masyarakat ini berhasil meningkatkan pemahaman masyarakat akan kandungan fitofarmaka dan manfaat minyak citronella, persyaratan obat herbal serta keterampilan teknis pembuatan citronella massage oil dan citronella massage oil for baby (minyak telon). Promosi produk yang telah dihasilkan KTH Agro Sumber Rejeki diharapkan dapat ditingkatkan baik melalui media sosial maupun keikutsertaan dalam pameran tingkat daerah maupun nasional.

\section{DAFTAR PUSTAKA}

[1]. O. I. Adeniran dan E. Fabiyi. "A Cream Formulation Of An Effective Mosquito Repellent: A Topical Product From Lemongrass Oil (Cymbopogon Citratus) Stapf". Journal Natural Product Plant Resources, Vol. 2 (2), pp. 322-327. 2012.

[2]. Ali B., Naser Ali Al-Wabel, Saiba Shams, Aftab Ahamad, Shah Alam Khan dan Faroz Anwar, "Essensial Oil Used In Aromatheraphy : A Sistematic Review", Journal Of Tropical Biomedicine. Vol. 5(8), pp. 601-611. 2015.

[3]. Indrasari, D., Wulandari, C. dan Bintoro, A. "Pengembangan Potensi Hasil Hutan Bukan Kayu Oleh
Kelompok Sadar Hutan Lestari Wana Agung Di Register 22 Way Waya Kabupaten Lampung Tengah". Jurnal Sylva Lestari. Vol. 5(1), pp. 81-91. 2017.

[4]. Setyaningsih, D., Hambali, E. dan Nasution, M. "Aplikasi Minyak Sereh Wangi (Citronella Oil) Dan Geraniol Dalam Pembuatan Skin Lotion Penolak Nyamuk". Jurnal Teknik Industri Pertanian, Vol. 17(3), pp. 97-103. 2010.

[5]. Nollet, L.M.L. dan Rathore, H.S. "Green Pesticides Handbook Essential Oils For Pest Control". https://www.routledgehandbooks.co $\mathrm{m} / \mathrm{doi} / 10.1201 / 9781315153131$.

2017.

[6]. Muhtaridi."Penelitian

Pengembangan Minyak Atsiri Sebagai Aromaterapi Dan Potensinya Sebagai Produk Sediaan Farmasi". Jurnal Teknik Industri Pertanian. Vol. 17 (3), pp. 80-88. 2010.

[7]. Hongratanaworakit, T. dan Soontornmanokul, S. "Development of Aroma Massage Oil For Relieving Muscle Pain And Satisfaction Evaluation In Human". Journal of Applied Pharmaceutical Science. Vol. 8(4), pp. 126-130. 2018.

[8]. Eden W T, Alighiri D, Cahyono E, Supardi K I dan Wijayati N. "Fractionation of Java Citronella Oil And Citronellal Purification By Batch Vacuum Fractional Distillation". IOP Conf. Series: Materials Science and Engineering. Vol.349, pp. 1-8. 2018.

[9]. Nirwana, W.O.C., Cahyani, C. dan Nurhadianty, V. "Kajian Daya Proteksi Produk Repelan Nyamuk Demam Berdarah Dengue Dalam Bentuk Lotion Berbasis Minyak Atsiri Lokal (Minyak Sereh Wangi Dan Minyak Nilam)". Jurnal Teknik Kimia. Vol. 11(1), pp. 1-6. 2016. 
[10]. Chang, Y., Lin C. dan Chang, L.. "The Effects Of Aromatheraphy Massage On Sleep Quality Of Nurses On Monthly Rotating Night Shifts", Hindawi Evidence-Based Complementary And Alternative Medicine, Vol. 2017, pp. 1-8, https://doi.org/10.1155/2017/38612 73. 2017. 